\title{
Relationship Between Trading Volume And Stock Exchange Performance: A Case From Karachi Stock Exchange
}

Faid Gul, National University of Modern Languages, Islamabad Tariq Javed, Mohammad Ali Jinnah University, Islamabad

\begin{abstract}
Over the past fifty years, much work has been done trying to understand the relationship between volume and price changes of individual stocks. In this article, we attempt to introduce and discuss some of these articles and take inference for relationship of traded volume and aggregate stock exchange index performance. This article presents an empirical analysis of the relationship between trading volume and performance of stock exchange index on a given day in the Pakistani market. Just like individual stocks, the relationship between changes in KSE 100 index and trading volume, irrespective of the direction of the index change, is significantly positive across all three alternative measures of daily trading volume (the daily number of shares traded; the daily total monetary value of shares traded; the daily number of equity trades).
\end{abstract}

Keywords: Volume, price changes, index volatility, volume-return relation, technical analysis

\section{INTRODUCTION}

C

tock Exchanges play a very important role in the economic development of a country. They help to provide liquidity to investors, on one hand, whereas to help businesses generate new capital on the other hand. Well-functioning secondary markets are taken as an indicator of the economic development of a country (Levine and Zervos 1996). Efficient secondary markets help countries to attract foreign direct as well as portfolio investment. These markets are very essential for developing countries to help boost their economies and catch up with the developed world.

Well-functioning secondary markets are based on timely, accurate and reliable information. Technical Analysis is one such tool to provide this information in an efficient manner. Technical Analysis uses the readily available market data to predict the future performance of individual securities, as well as the aggregate stock exchange index. An extensive literature is available on Technical Analysis of individual securities, but there is not much research done in the field of using Technical Analysis to predict the performance of aggregate stock exchange index, particularly in Pakistan. This research is an attempt to use Technical Analysis to predict the performance of aggregate stock exchange index by using daily data of Karachi Stock Exchange. Its findings will be helpful for investors to better time their investment decisions. It will also be helpful for professional fund managers, like mutual funds, pension funds, insurance companies, and alike, to form optimal portfolios.

\section{LITERATURE REVIEW}

A number of research studies concluded that stock prices follow a random path as do the aggregate stock exchange indices. This is justified on the grounds that the creation of information is random and price discovery is based on information, so prices of securities should follow random path. On the other hand, an equal number of research studies rejected the random walk theory and efficient market hypothesis and identified a number of anomalies, like size effect, day of the week effect, short interest ratio effect, mutual funds' cash ratio effect, and odd-lot ratio effect (Benton, 1973). 
According to Persons and Frickey (1926), substantial quantitative changes in money rates, regardless of the length of time during which those changes take place, have been, in general, highly significant for security markets. Academic treatment of a price-volume relation can be traced to Osborne (1959) who attempted to model the stock price change as a diffusion process with variance dependent on the number of transactions. This could imply a positive correlation between volume and absolute price change, as later developed by Clark (1973) and Tauchen and Pitts (1983). Tauchen and Pitts studied the relationship between the variability of the daily price change and the daily volume of trading on the speculative markets. However, by assuming transactions are uniformly distributed in time, Osborne was able to re-express the price process in terms of time intervals and did not directly address the volume-price issue Blume, Easley, and O'Hara (1994) emphasize the crucial role of transaction volume as a statistic for technical analysis. It is this multi-market linkage of price, volume, and information that is the focus of our research. Black and Fisher (1975) first suggested that the higher leverage available in options markets might induce informed traders to transact options rather than stocks. Sheikh and Ronn (1994), Mayhew, Sarin, and Shastri (1995), Fleming, Ostdiek, and Whaley (1996) have empirically investigated the links between options and equity markets. These are the technical indicators that are used to predict the future prices of securities.

While going through the research, it is observed that trading volume is positively linked to the absolute value of price changes. The evidence linking trading volume and price changes is mixed. The relationship between trading volume and securities prices is a complex one when understood properly and can lead to many insights in portfolio theory. Investors usually go toward their primary interest while looking at the stock market i.e. prices of shares. They ignore the other aspect of trading i.e. volume data and number of transactions. The Efficient Market Hypothesis introduced by Fama (1965) states that in an efficient market, there are a large number of "rational profitmaximizers" that actively compete, each trying to predict future market values. The interaction of these participants causes the current price to fully reflect the expectation of the future price of the security. In essence, the more efficient a market, the more unpredictable future pricing will be, with the expected value of future prices equal to the current price. It may be argued that historical equity returns in the stock market have been positive over the long run, thus making this hypothesis questionable (Walter Sun, area exam report, 2003).

One important factor in the determination of prices is the volume traded. Volume is measured in different ways. On one hand, it is defined as a measure of the quantity of shares that change owners for a given security while, on the other hand, it is measured as the number of trades (total number. of transactions) that take for a certain security or for the aggregate market. Still, others define it as the monetary value of total traded shares. All three measures are widely used by researchers. The amount of daily volume on a security can fluctuate on any given day depending on the amount of new information available about the company, whether options contracts are set to expire soon, whether the trading day is a full or half day, and many other possible factors.

Stock indices are heavily depended on the prices of shares throughout the world. So, the basic question is "why relate the trading volume and its relationship to prices?" Karpoff (1987) suggests that there are four possible reasons. First, it adds insight to the structure of financial markets. Second, use of a combination of price and volume data to draw inferences is needed to properly understand this relationship. Third, understanding the price-volume relationship in futures and other speculative markets is vital for one to determine why the distribution rates of return appear kurtosis. Fourth, price variability affects trading volume in future contracts. This interaction determines whether speculation is a stabilizing or destabilizing factor on futures prices. In the absence of clear financial information, investor decisions are swayed by the aesthetics of financial reports (Smith, 2003). Richardson, Sefcik \& Thompson (1986) have used volume and price changes to determine that shareholders hold securities primarily because of dividend yields. It can be imagined that the validity of many of these inferences rely on the relationships between price and volume. The volume corresponding to a price change due to new information indicates how much investors differ in the interpretation of the new data (Beaver, 1968). Sometimes information on a company can impact the volume and price of another unrelated company due to the sheer similarity of the ticker symbol (Rashes, 2001).

French and Roll (1986) show that volatility in securities prices is higher during trading hours. On an equivalent hourly basis, French and Roll documented that volatility during trading hours on the NYSE is far greater than during weekend non-trading hours, and they concluded that the greater variance during trading time is due to the arrival of private (rather than public) information. Karpoff (1988) also concludes that there is only weak 
evidence supporting a relationship between volume and price change per se. Short selling can be incorporated into the model which results in an asymmetric relationship between volume and price change.

Another model which predicts an asymmetric relationship between trading volume and price changes is that originally proposed by Epps (1975) and developed by Jennings, Starks and Fellingham (1981). In this model, investors are classified as either "optimists" or "pessimists". Again, short positions are assumed to be more costly than long positions. In such a market, investors with short positions would be less responsive to price changes. Jennings, Starks, and Fellingham (1981) show that (generally) when the trader is a pessimist, the trading volume is less than when the trader is an optimist. Since prices decrease with a pessimistic seller and increase with an optimistic buyer, it follows that volume is low when prices decrease and high when prices increase.

Investors may be heterogeneous with respect to their investment opportunities and/or with respect to the information with which they are trading. Under traditional asset pricing models with complete markets and homogeneous investors, trading volume does not provide any significant information about prices. According to Wang (1994), this is because in such models, with representative agents, the specification of aggregate risk determines the optimal allocation of assets, along with asset prices. He further developed a model of rational expectation linking trading volume to stock prices volatility under asymmetric information. He finds a positive relation between trading volume and absolute changes in stock prices but informed and uninformed investors behave differently in his model. Where as Harris and Raviv (1991) developed a model which determines price change and trading volume correlation. Admati and Pfleiderer (1988) provide evidence that volume and price movements are clustered in time because traders who have the choice of timing their trades at their discretion choose to trade when recent volume is large. Their multi-period model assumes that traders are motivated by either information or liquidity. All traders do not share the same information and informed traders trade when they have some private information. The liquidity or noise traders are motivated by factors other than expected payoffs through future price movements. Institutional traders may be trading due to liquidity needs of their clients. The strategic timing of trading partially explains the positive relation between trading volume and the variability of stock returns.

Granger and Morgenstern (1963) and Godfrey, Granger and Morgenstern (1964) use weekly data to examine the relation between price changes and volume and find price changes follow a random walk. Crouch (1970) finds a positive correlation between daily volume and absolute values of daily price changes for both market indexes and individual stocks. Silvapulle and Choi (1999) use daily Korean Composite Stock Index data to study the linear and non-linear Granger causality between stock price and trading volume, finding that there is a significant bi-directional linear and non-linear causality between the two series. Movements in the stock market are not only linked with the stock market index but also used as an indicator for the economic development; the idea is supported by Levine and Zervos (1996). They found that stock market development was strong positively correlated with economic growth.

The above cited articles and much of the technical analysis research is in the field of predicting future prices of individual securities. This research will add to the existing body of literature by taking aggregate stock exchange index as an indicator.

\section{HYPOTHESES}

Until now two distinguishing characteristics have emerged, within the equity markets, involving the relationship between individual stock price changes and trading volume. The first characteristic is that the absolute value of price changes is positively correlated with trading volume. That is, large positive and large negative price changes are associated with large trading volume. Second, studies show that the price-volume relationship when prices are increasing is different from the price-volume relationship, when prices are decreasing (Long, 2007).

None of these studies have used aggregate stock exchange index as an indicator for analysis. For this research, we are studying correlation between aggregate stock exchange index and aggregate volume traded on a given day at Karachi Stock Exchange. Formally stated, the hypotheses for the aggregate stock exchange index and volume relationship are as follows: 


\section{Hypothesis 1}

$\mathbf{H}_{\mathbf{0}}$ : The value of aggregate stock exchange index is uncorrelated with the volume of share traded.

$\mathbf{H}_{\mathrm{A}}$ : The value of aggregate stock exchange index is positively correlated with the volume of share traded.

\section{Hypothesis 2}

$\mathbf{H}_{\mathbf{0}}$ : The value of aggregate stock exchange index is uncorrelated with the monetary value of share traded.

$\mathbf{H}_{\mathrm{A}}$ : The value of aggregate stock exchange index is positively correlated with the monetary value of share traded.

\section{Hypothesis 3}

$\mathbf{H}_{0}: \quad$ The value of aggregate stock exchange index is uncorrelated with the number of equity trades.

$\mathbf{H}_{\mathrm{A}}$ : The value of aggregate stock exchange index is positively correlated with the number of equity trades.

\section{DATA AND METHODOLOGY}

\subsection{Sample Selection}

Daily data are collected from the website of Karachi Stock Exchange for KSE 100 index and all three measures of volume. This research is based on closing value of KSE 100 index and the closing values of volume data. Daily data of a total of 92 days are collected starting from June 18, 2007 to October 31, 2007, grossly covering the first quarter of fiscal year 2007-08. Since we are not using the data for price changes of individual stocks, therefore, no adjustments are made for dividends, bonus shares, and stock splits during this period. Descriptive statistics are used to study the relationship between KSE 100 Index performance and measures of volume data.

\subsection{Method of Research}

We use a correlation method for this research study. In this study, the performance of KSE 100 Index is the dependent variable whereas the three measures of volume, on Karachi Stock Exchange at a given day, are independent variables. A simplified model of this research is given below. Correlation method is used to predict the performance of KSE 100 Index when these independent variables are changing. This research article also studies correlation among independent variables.

Independent Variables

Dependent Variables

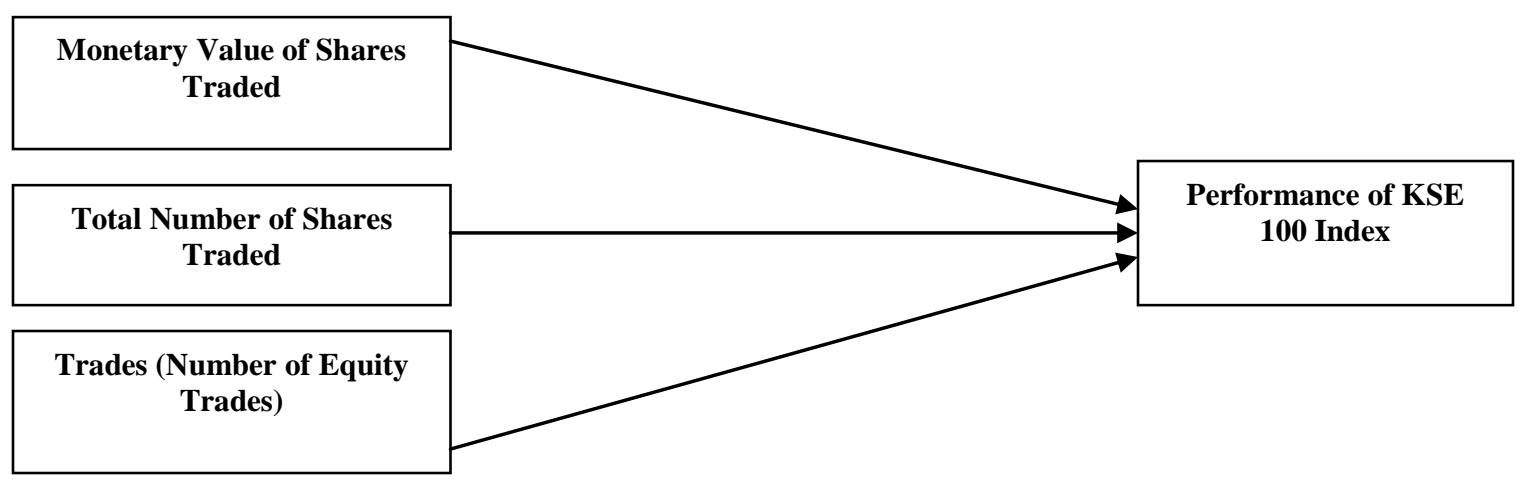




\subsection{Tests of Hypotheses}

The above three hypotheses test whether aggregate stock exchange index increases and decreases are significantly correlated with levels of trading volume. Volume can be measured in three different ways; therefore, this research tests all three measures of volume data. Hypothesis 1 tests whether aggregate stock exchange index is significantly correlated with the total number of shares traded on a given day at KSE. Hypothesis 2 tests whether aggregate stock exchange index is significantly correlated with the monetary value of shares traded (traded value) on a given day at KSE. Hypothesis 3 tests whether aggregate stock exchange index is significantly correlated with the number of equity trades on a given day at KSE. Data are also tested for significant correlation among independent variables used in this study. Simple correlation is used to study the nature and extent of correlation among the stated variables. This study uses actual values to study the relation, whereas it is possible to use percentage values for the same purpose.

\section{DESCRIPTIVE STATISTICS}

The performance of KSE from June 18, 2007 to October 31, 2007 is summarized in the following two tables. Table 1 shows different measures of KSE 100 Index performance along with three measures of volume data. It shows Mean and Median values of all these variables for the above stated time period. To check the volatility of these variables we calculate Standard Deviation. As standard deviation is affected by magnitude of original values therefore we calculate Coefficient of Variance (CV) to make it standardized. Table 1 shows that KSE 100 Index was more stable during the above stated time period relative to volume data. Table 2 shows the average transaction size at KSE in the above stated time. With a minimum trading lot of 500 shares per transaction, Table 2 shows a very high number of shares traded per transaction. This may be attributed to trading from financial institutions like mutual funds, pension funds, and insurance companies.

Table 1: Descriptive statistics for KSE 100 Index and measures of volume data

\begin{tabular}{|c|c|c|c|c|}
\hline Item & Mean & Median & STDEV & CV \\
\hline KSE 100 Index & $13,425.50$ & $13,560.58$ & 715.50 & 0.05 \\
\hline Vol. of Shares Traded & $278,182,683.35$ & $268,698,980.00$ & $95,770,680.50$ & 0.34 \\
\hline Monetary Value of Shares Traded & $34,312,805,963.00$ & $24,219,983,342.50$ & $9,233,696,182.16$ & 0.36 \\
\hline No. of Equity Trades & $103,355.85$ & $101,037.50$ & $22,330.77$ & 0.22 \\
\hline
\end{tabular}

Table 2: Average transaction size traded at Karachi Stock Exchange

\begin{tabular}{|c|c|}
\hline Item & Value \\
\hline Avg. Vol. of Shares Traded/Equity Trade & $2,691.50$ \\
\hline Avg. Monetary Value of Shares Traded/Equity Trade & $246,579.29$ \\
\hline
\end{tabular}

\section{RESULTS}

All three hypotheses test the nature and extent of correlation between aggregate stock exchange index performance and measures of volume data. Table 3 confirms that there is a significant positive correlation between aggregate stock exchange index performance and all the measures of volume data of Karachi Stock Exchange. The extent of positive correlation between aggregate stock exchange index performance and measures of volume data is in the range of $0.66-0.70$ which shows a very strong positive correlation. On the other hand, the extent of positive correlation among independent variables is in the range of 0.78-0.91 which shows an even more strong correlation among independent variables. As independent variables are significantly positive correlated with each other this provides further evidence about a strong positive correlation between aggregate stock exchange index and measures of volume data. Table 3 provides the summarized data about correlation among different variables. 
Table 3: Tests results for correlation between aggregate stock exchange index performance and volume data

\begin{tabular}{|c|c|c|c|c|}
\hline Variable & KSE 100 Index & $\begin{array}{c}\text { Vol. of Shares } \\
\text { Traded }\end{array}$ & $\begin{array}{c}\text { Monetary Value of } \\
\text { Shares Traded }\end{array}$ & $\begin{array}{c}\text { No. of Equity } \\
\text { Trades }\end{array}$ \\
\hline KSE 100 Index & 1.000 & - & - & - \\
\hline Vol. of Shares Traded & 0.699 & 1.000 & - & - \\
\hline Monetary Value of Shares Traded & 0.696 & 0.777 & 1.000 & - \\
\hline No. of Equity Trades & 0.663 & 0.907 & 0.798 & 1.000 \\
\hline
\end{tabular}

\section{CONCLUSIONS}

Several studies have found a correlation between stock price changes and trading volume within the equity and option markets. All of these studies used absolute price changes and volume traded for individual securities. There are no studies that have examined such a relation between aggregate stock exchange index and volume data at Karachi Stock Exchange. This study provides the first evidence that a similar relationship exists for aggregate stock exchange index and volume data. To study the relation, this study used normal changes in aggregate stock exchange index instead of absolute changes used in previous studies. This paper tests the correlation of aggregate stock exchange index and all three measures of volume data.

A significantly positive correlation is found between aggregate stock exchange index and all three measures of volume data at Karachi Stock Exchange. Since this study used normal changes in aggregate stock exchange index and volume data, this implies that large levels of volume are associated with increases in aggregate stock exchange index at a given day. Similarly, low levels of volume are associated with decreases in aggregate stock exchange index. Similar to prior findings in the equity and option markets for individual securities, aggregate stock exchange index also shows that positive changes in aggregate stock exchange index are associated with significantly higher volume levels and vice versa. Therefore, this research provides evidence that the price-volume relationship found in the equity and option markets also exists for aggregate stock exchange index and volume data on a given day at Karachi Stock Exchange.

\section{AUTHOR INFORMATION}

Mr. Faid Gul, BBA, MBA, MS (Finance) is Lecturer of Accounting and Finance at National University of Modern Languages Islamabad, Pakistan. He earned his BBA and MBA degrees from International Islamic University, Islamabad with Bronze Medal, Gold Medal and distinctions, respectively and his MS (Finance) degree from Mohammad Ali Jinnah University, Islamabad with Gold Medal and very high distinction. He is an author of two research articles published in NUML Journal of Management \& Technology. He is also a member of the Research Committee of Department of Management Sciences at National University of Modern Languages, Islamabad.

Mr. Tariq Javed (MS Finance) lecturer of Accounting \& Finance at Mohammad Ali Jinnah University Islamabad, Pakistan. Graduation from Punjab University, MBA from National University of Modern Languages, PIPFA from Pakistan Institute of Public Finance Accountants Karachi, MS from Mohammad Ali Jinnah University Islamabad. He also served as an Assistant Audit Officer in Pakistan Audit Department.

\section{REFERENCES}

1. Admati, A. D. and Pfleiderer, P., (1988). A theory of intraday patterns: Volume and price variability. Review of Financial Studies 1, 1-40.

2. Benton, E. G., (1973). A Note on Stock Market Indicators and Stock Prices. The Journal of Financial and Quantitative Analysis, Vol. 8, No. 4. (Sep., 1973), pp. 673-682.

3. Black, F., (1975). Fact and fantasy in use of options. Financial Analysts Journal 31, 36-41, 61-72.

4. Blume L., Easley D., and O'Hara, M. (1994). Market statistics and technical analysis: The role of volume. Journal of Finance 49, 153-181.

5. Clark, P. K., (1973). A Subordinated Stochastic Process Model with Finite Variance for Speculative Prices. Econometrics, 41 (Jan. 1973), 135- 155. 
6. Crouch, R. L., (1970). The Volume of Transactions and Price Changes on the New York Stock Exchange. Financial Analysts Journal, 26, 104-109.

7. Epps, T. W., (1975). Security Price Changes and Transaction Volumes: Theory and Evidence, American Economic Review, September, Vol.65, pp.586-597.

8. $\quad$ Fama, F. E., (1965). Random walks in stock market prices. Financial Analysts Journal, Sept/Oct 1965.

9. Fleming, J., Ostdiek, B., and Whaley E. R., (1996). Trading costs and the relative rates of price discovery in stock, futures, and option markets. Journal of Futures Markets 16, 353-387.

10. French, K. R. and Roll, R., (1986). Stock Return Variances: The Arrival of Information and the Reaction of Traders. Journal of Financial Economics, Vol.17, pp.5-26.

11. Godfrey, M. D., Granger, C. W. J., Morgenstern, O., (1964). The Random-walk Hypothesis of stock Market Behavior. Kyklos 17, 1-30.

12. Granger, C. W. J., and Morgenstern, O., (1963). Spectral Analysis of New York Stock Market Prices. Kyklos, 16, 1-27.

13. Harris, M. and Raviv, A., (1991). Differences of opinion make a horse race. Review of Financial Studies 6, 473-506.

14. Jennings, R. H., Starks, L. T. and Fellingham, J. C., (1981). An Equilibrium Model of Asset Trading with Sequential Information Arrival. Journal of Finance, March, Vol.36, pp.143-161.

15. Karpoff, J. M., (1987). The Relationship between Price Changes and Trading Volume. Journal of Financial and Quantitative Analysis, Vol. 22, Iss. 1: 109-126.

16. Karpoff, J. M., (1988). Costly Short Sales and Correlation of Returns with Volume. Journal of Financial Research, Vol. 11, Iss. 3: 173-188.

17. Levine, R. and Zervos, S., (1996). Stock Market development and long-run growth. World Bank Economic Review, Vol.10, No.2 323-339.

18. Long, D. M., (2007). An Examination of the Price-Volume Relationship in the Option Markets. International Research Journal of Finance and Economics, Iss. 10: 47-56.

19. Mayhew, S., Sarin, A., and Shastri, K., (1995). The allocation of informed trading across related markets: An analysis of the impact of changes in equity-option margin requirements. Journal of Finance 505, 16351654.

20. Michael S. R., (2001). Massively confused investors making conspicuously ignorant choices (MCIMCIC). Journal of Finance, 56(5):1911-1927.

21. Osborne, M. F. M., (1959). Brownian Motion in the Stock Market. Operations Research, 7 (March-April 1959), 145- 173.

22. Persons, M. W. and Frickey E., (1926). Money Rates and Security Prices. The Review of Economic Statistics, Vol. 8, No. 1. (Jan., 1926), pp. 29-46.

23. Richardson, G., Sefcik, S. E., and Thompson, R., (1986). A test of dividend irrelevance using volume reaction to a change in dividend policy. Journal of Financial Economics, 17(12):313-333.

24. Sheikh, A. M., and Ehud I. R., (1994). A characterization of the daily and intraday behavior of returns on options. Journal of Finance 49, 557-580.

25. Silvapulle, P., and Choi, J.S., (1999). Testing for Linear and Nonlinear Granger Causality in the Stock Price-volume Relation: Korean Evidence. Quarterly Review of Economics and Finance 39, 59-76.

26. Stephanie D. S., (2003). The Ticker. Money Magazine, 1:22.

27. Tauchen, G. E. and Pitts, M., (1983). The Price Variability-Volume Relationship on Speculative Markets. Econometrica, Vol. 51, No. 2. (Mar., 1983), pp. 485-505.

28. Walter Sun Area Exam Report. Relationship between Trading Volume and Security Prices and Returns. MIT Laboratory for Information and Decision Systems, Technical Report P-2638.

29. Wang, J., (1994). A model of competitive trading volume. Journal of Political Economy, 102, 127-168.

30. William H. B., (1968). The information content of annual earnings announcements. Empirical Research in Accounting: Selected Studies; suppl. to Journal of Accounting Research, 6:67-92. 
International Business \& Economics Research Journal - August 2009 Volume 8, Number 8 NOTES 